\title{
A PERSPECTIVA LIBERTADORA DA EDUCAÇÃO: UMA ANÁLISE DO PENSAMENTO FREIRIANO E SUAS CONTRIBUIÇÕES NA ATUALIDADE
}

\author{
Flavia CAVAlCANTE Nicolis de Medeiros \\ Centro Universitário Autônomo do Brasil (UNIBRASIL), Curitiba, Paraná, Brasil
}

Resumo: O objetivo deste artigo consiste em introduzir um debate acerca de Paulo Freire e suas contribuições à Educação brasileira. Nesse sentido, são abordados os elementos fundamentais do seu pensamento, suas obras e suas propostas pedagógicas, bem como as principais críticas a essa perspectiva, inclusive do projeto "Escola sem Partido". Na sequência, são apresentadas as posições de Paulo Freire diante de algumas dessas críticas e a visão do autor sobre o papel da Educação na sociedade. Visando alcançar o escopo deste artigo, o recurso metodológico utilizado baseia-se numa pesquisa bibliográfica e documental, associada a uma análise crítica da realidade brasileira na contemporaneidade. Conclui-se que as propostas de Paulo Freire permanecem atuais e imprescindíveis no enfrentamento dos grandes e complexos desafios da Educação no Brasil.

Palavras-chave: Paulo Freire. Educação libertadora. Propostas pedagógicas. Conservadorismo.

\section{INTRODUÇÃO}

O Brasil se configura como um país caracterizado por séculos de exclusão e opressão, determinados historicamente pela escravidão, pelo latifúndio e pela precariedade dos bens de consumo para a maioria da população. Desse modo, foi legada ao povo brasileiro a prática da desumanização e a incapacidade de se reconhecer enquanto sujeitos de direitos.

\begin{abstract}
Portanto, a escravidão negra, a aculturação dos indígenas, a submissão e o maltrato das mulheres solidificaram historicamente, a negação, intencional e sistemática, dos Direitos Humanos à maioria dos brasileiros e brasileiras. A violência generalizada contra o povo inclui a praticada por parte do Estado, relegando para o campo da indiferença o destino de seus homens, mulheres e crianças [...]. (FREIRE; MENDONÇA, 2019, p. 17-18).
\end{abstract}

Deve-se ressaltar que, desde o início da década de 1980, a filósofa Marilena Chauí tem argumentado que a sociedade brasileira é autoritária e violenta. Inclusive, no seu livro Cultura e Democracia (2006), a autora desconstrói a imagem de uma cultura nacional "acolhedora e cordial", revelando estruturas autoritárias, por exemplo, o escravismo e as ditaduras, historicamente pautadas em relações de poder de caráter patriarcal, machista e autoritário. Isso não significa que o brasileiro, individualmente, seja 
violento, mas que essas estruturas mencionadas se constituíram historicamente no Brasil dessa forma. A resultante desse processo tem sido o fortalecimento da violência e do autoritarismo que, na atualidade, se intensificam nas formas de controle social e na ausência de um amplo debate político por parte da direita e, também, da esquerda, prejudicando a configuração da democracia em nosso país (CHAUí, 2006). Na contemporaneidade, a extrema direita tem se configurado em todo o mundo, com destaque para países da Europa e nos Estados Unidos, bem como na América Latina. Assim sendo, no Brasil se constituíram movimentos ultraconservadores que resultaram no golpe de 2016, afastando a Presidenta Dilma Rousseff e viabilizando a eleição de Jair Bolsonaro. A despeito das especificidades da extrema direita em cada país, há evidentes similaridades nesses governos - o autoritarismo, o nacionalismo, a intolerância religiosa ou étnica (racista) e às minorias sexuais, a violência policial/militar (LÖWY, 2019, p. 1-2 citado por MIRANDA, 2019, p. 9).

Nesse quadro, a educação brasileira tem sido alvo de ofensivas contundentes visando a sua mercantilização e privatização em todos os níveis, pautadas no neoliberalismo de viés autoritário e conservador que tem aprofundado a desigualdade social de modo brutal. Assim, o princípio da responsabilidade do Estado pela educação pública vai sendo desconstruído ou deslocado para o atendimento exclusivo dos segmentos muito pobres (MIRANDA, 2019).

Paulo Freire tem sido alvo preferencial desses ataques ultraconservadores por parte do atual governo brasileiro, sobretudo pelo Ministério da Educação, que visam desqualificar a obra do autor. Deve-se enfatizar que Paulo Freire é Patrono da Educação brasileira desde 2012 (Lei n. 12.612/12), em reconhecimento às suas relevantes contribuições no campo da Educação, pelo seu empenho em democratizar o acesso à educação e por lutar por uma Escola pública de qualidade, pela igualdade e inclusão dos segmentos sociais populares historicamente alijados da sociedade (FREIRE; MENDONÇA, 2019).

Paulo Freire dedicou toda sua vida à reflexão/intervenção acerca do papel da Educação, do Professor e da Escola na construção de uma nova sociedade mais justa, humana e igualitária. Por conseguinte, o autor se constitui, na atualidade, em uma referência importante no debate acerca dos desafios postos nos rumos da educação brasileira, assim como para refletir sobre a práxis política (VAZQUEZ, 1977), sendo sua trajetória um exemplo de ética, dignidade e coragem. Suas convicções mais íntimas residiam na coerência entre o falar e o agir, na humildade, no respeito às diferenças, no gosto salutar pelo debate de ideias. É interessante observar como Paulo Freire cativou e cativa tantas pessoas, ao mesmo tempo em que provoca a irritação e aversão de tantas outras, e como suas teses têm sido incorporadas em áreas de saber diversas, não somente às vinculadas às Ciências Humanas, mas também, em áreas tão distintas, como Saúde (LOPES et al., 2017) e Tecnologia (ZAIUTH; HAYASHI, 2011).

Deve-se sublinhar que no Brasil emergem propostas conservadoras e autoritárias a partir do chamado movimento "Escola sem Partido", criado em 2004, que mais tarde se consubstanciou num projeto com a mesma denominação, colocando em risco conquistas democráticas históricas relacionadas à garantia do direito à educação em nosso país. Os referidos movimento e projeto demonstram "preocupação com a suposta contaminação político-ideológica" nas escolas brasileiras e objetivam ações 
para conter tais práticas pedagógicas, sendo Paulo Freire um dos principais alvos de ofensivas desses grupos ultraconservadores, como mencionado. Assim, tais grupos buscam restringir e vigiar a ação do professor, visando estabelecer uma educação moldada sob os ditames da família patriarcal e do apego à religião cristã de viés conservador (FLACH; DARCOLETO, 2019).

Nessa direção, a escola é subtraída do seu papel de educar as novas gerações, pautada no conhecimento historicamente construído pela humanidade, e se limitaria ao papel tecnicista de formação para o trabalho. Além disso, há a pressão e o estímulo de denúncias por parte de alunos e pais contra os professores que não sigam tais preceitos conservadores. Também há a tentativa de impedir a abordagem pedagógica de questões relativas à sexualidade e ao gênero, presentes nos conteúdos curriculares da educação brasileira na atualidade. Tal interdição demonstra preconceitos, fomentando a homofobia ancorada no moralismo. Deve-se frisar que tais particularidades do pensamento conservador contemporâneo estão presentes nas propostas educacionais em curso no Brasil (FLACH; DARCOLETO, 2019).

Ademais, verifica-se a busca de controle ideológico da escola, com práticas autoritárias diversas, visando atacar os processos democráticos e participativos da educação e seus preceitos básicos, como o respeito ao espaço da escola e da sala de aula, pautados pelos princípios de autonomia e liberdade de expressão do professor.

Do ponto de vista ideológico, a propagação e a naturalização de crenças terraplanistas, criacionistas e outros obscurantismos de toda ordem passam a desacreditar as diferentes manifestações do pensamento racional [...] que contrariem qualquer preceito real ou imaginário dos interesses dominantes [...]. (MIRANDA, 2019, p. 11).

Portanto, o projeto "Escola sem Partido" afronta os preceitos constitucionais de liberdade de cátedra, pluralismo de concepções pedagógicas, valorização dos profissionais de educação, gestão democrática do ensino público, bem como o respeito e a tolerância à diversidade étnico-racial e de gênero e orientação sexual. Tal projeto reforça interesses econômicos, políticos e particulares de grupos sociais conservadores, ancorados em discursos religiosos fundamentalistas, que têm colocado a escola e o professor como "inimigos" que devem ser derrotados, por isso, representa um risco às conquistas democráticas, como o direito à educação (FLACH; DARCOLETO, 2019).

Desse modo, na atualidade, torna-se premente a resistência democrática da sociedade civil organizada na defesa dos direitos historicamente conquistados pelas árduas e legítimas lutas das classes trabalhadoras, como também na defesa das Políticas Públicas, sobretudo, a Educação e a Saúde, em conformidade com o que preceitua a Constituição Federal do Brasil de 1988. Pois, o acesso às condições básicas de vida da população é dever do Estado e direito de cidadania, configurando os fundamentos da República e do Estado Democrático de Direito.

No que se refere ao percurso metodológico utilizado para a elaboração deste artigo, consiste em uma pesquisa bibliográfica e documental (GIL, 2012) que aborda o pensamento de Paulo Freire, suas propostas pedagógicas e as críticas presentes no debate acerca das ideias e da prática freiriana. Dentre os aspectos de destaque na pesquisa realizada estão os elementos fundamentais do pensamento de Freire, suas 
obras e propostas pedagógicas. Adicionalmente, nesta aproximação ao debate sobre o autor, são relacionadas também as principais críticas à perspectiva freiriana, inclusive o projeto "Escola sem Partido" (RIO DE JANEIRO, 2016; DUTRA; MORENO, 2016; ALEIXO; ALMEIDA, 2017; FLACH; DARCOLETO, 2019).

Além desta introdução, o artigo está organizado em mais quatro seções que abordam a trajetória do autor e suas propostas pedagógicas; as principais críticas ao pensamento freiriano e às suas práticas, tanto de segmentos da direita e da esquerda; além das seções de conclusão e referências.

\section{TRAJETÓRIA DE PAULO FREIRE E PROPOSTAS PEDAGÓGICAS}

Paulo Freire dedicou toda a sua vida à reflexão/intervenção sobre a prática educativa, o papel da Escola e do Professor na construção de uma sociedade mais justa, mais humana e mais igualitária. Nessa direção, o autor sempre buscou a democratização do acesso à educação pública de qualidade que visava à conscientização e à participação política, sobretudo das classes populares, historicamente excluídas da sociedade. Sendo assim, tais segmentos sociais espoliados poderiam emergir da sua condição de dominados através de sua politização expressa na leitura da palavra e na leitura do mundo. O chamado "Método Paulo Freire" foi criado a partir desses suportes político-pedagógicos que expressam uma crítica à realidade injusta, discriminatória e desigual que vivemos e que precisa ser superada, embora não seja consensual entre os estudiosos do autor. Naquele período, as propostas do autor, radicalmente democráticas e inovadoras, trouxeram como consequência a prisão e o exílio de seu idealizador (considerado subversivo) pelo governo militar, a partir do golpe de 1964, em nosso país. É interessante observar que, ao ser interditada sua presença no Brasil, Paulo Freire pôde divulgar seu pensamento, seus ideais e suas experiências em diversos países do mundo, adquirindo o reconhecimento, o respeito e a admiração que lhe são devidos (PLÁCIDO; SOUZA, 2017; FREIRE, 2006a; GADOTTI, 2001; CASALI, 1998).

A fecunda e relevante obra de Paulo Freire, particularmente, o livro Pedagogia do Oprimido (FREIRE, 1987), tem sido publicada em todo o mundo em diversos idiomas e alimentado polêmicas em torno do papel da Educação, do Professor e da Escola na sociedade. Neste cenário, observam-se desde manifestações de solidariedade, admiração e adesão até a tentativa de desqualificar o autor devido ao caráter "demasiado político" de suas teses que seria "incompatível" com a educação.

Verifica-se que a trajetória pessoal do autor influenciou diretamente no processo de construção de sua obra. Nesse aspecto, o autor recorreu a diversos subsídios, como os relatos de sua infância e adolescência no Recife; o seu trabalho no Sesi (Serviço Social da Indústria), que viabilizou seu primeiro contato com os trabalhadores; mais tarde, no exílio, suas experiências em distintos países (Bolívia, Chile, Estados Unidos e África); e suas vivências junto aos intelectuais, estudantes, trabalhadores e lideranças políticas, muitos deles envolvidos em lutas concretas pela libertação, como o combate às diversas formas de discriminação, como as de classe, gênero, etnia e de orientação sexual (FREIRE, 2006a). 
Constata-se ainda que o autor tinha capacidade de autocrítica de suas ideias, como, por exemplo, no caso da suposta linguagem machista de seus textos apontada por feministas norte-americanas. Depois disso, o autor incorporou a definição de gênero na sua linguagem e nos seus textos (FREIRE, 1992). Já com relação às demais críticas que Ihe imputavam termos pejorativos, como "elitista" ou "populista" e a referência ao caráter "demasiado político" de suas propostas, o autor nunca se esquivou do debate, esclarecendo e aprofundando suas teses e não deixando de reiterar suas convicções: sua opção pelo projeto socialista; a atualidade da teoria marxista que engloba a luta de classes; a necessidade de transformar a sociedade capitalista; a recusa das posições dogmáticas; e a defesa de uma postura democrática radical (FREIRE, 2006a).

Nos textos do autor, verifica-se que o fio condutor de sua exposição se constitui na valorização do debate e do diálogo, no respeito às diferenças, na troca de experiências com distintos interlocutores visando a desvendar o papel da educação, da escola e do professor na sociedade (FREIRE, 2006a). Tal tarefa implica em compreender o significado do ato de ensinar-aprender, a identificação dos acertos e equívocos na práxis política (VAZQUEZ, 1977), o combate às posições sectárias e o compromisso com uma perspectiva democrática radical.

Paulo Freire é um dos pensadores brasileiros mais célebres e lidos no mundo. Escreveu dezenas de livros, dentre eles, $A$ Importância do ato de ler em três artigos que se completam (FREIRE, 1982); Pedagogia do Oprimido (FREIRE, 1987); Educação Como Prática da Liberdade (FREIRE, 2006b); A Educação na Cidade (FREIRE, 1991); Pedagogia da Esperança: um reencontro com a Pedagogia do Oprimido (FREIRE, 1992); Professora Sim, Tia não: cartas a quem ousa ensinar (FREIRE, 1993); Política e Educação (FREIRE, 1993); Cartas à Cristina: reflexões sobre minha vida e minha práxis (FREIRE, 1994); $A$ Sombra desta Mangueira (FREIRE, 1995); Pedagogia da Autonomia: saberes necessários à prática educativa (FREIRE, 1996); Pedagogia da Indignação: cartas pedagógicas e outros escritos (FREIRE, 2000); Pedagogia dos Sonhos Possíveis (FREIRE, 2001); Pedagogia da Tolerância (FREIRE, 2005); e Medo e Ousadia: O Cotidiano do Professor (FREIRE; SHOR, 2013).

Além disso, Paulo Freire é o brasileiro com maior número de diplomas de diferentes universidades no mundo, sendo homenageado com o título de "Doutor Honoris Causa" por 29 universidades, dentre elas, Harvard (EUA), Cambridge e Oxford (Inglaterra). Freire tem sido reconhecido e homenageado também por governos e órgãos internacionais, dentre os prêmios conquistados estão o "Prêmio Rei Balduíno para o Desenvolvimento" (Bélgica, 1980); "Prêmio UNESCO da Educação para a Paz" (1986) e "Prêmio Andres Belloda da Organização dos Estados Americanos" (OEA), como "Educador dos Continentes" (1992). (VEIGA, 2019; MENDES, 2019).

Paulo Freire é o terceiro pensador mais citado em trabalhos acadêmicos no mundo, sendo suas ideias citadas 72.359 vezes, ficando atrás somente dos americanos Thomas Khun e Everett Rogers. Dentre os 100 livros mais solicitados em ementas de universidades de língua inglesa em todo o mundo, o único livro brasileiro que aparece na lista é Pedagogia do Oprimido (FREIRE, 1987) que aparece em $99^{\circ}$ lugar no ranking geral, com 1.021 citações em programas de ensino. Os livros de Freire foram traduzidos para 20 idiomas diferentes e distribuídos em cerca de 80 países nos cinco continentes (VEIGA, 2019; MENDES, 2019). 
No que concerne ao sucesso do seu livro Pedagogia do Oprimido (FREIRE, 1987), o autor considera que este poderia ser explicado pelas suas teses que mantêm sua atualidade: a importância da consciência e da subjetividade nos processos sociopolíticos e culturais; o reconhecimento em nossa vida pessoal e social da relevância dos sentimentos, da paixão, dos desejos, do medo, da coragem de amar e de se indignar; a defesa veemente de posições humanistas; a compreensão da história; a recusa de posições dogmáticas e sectárias; o gosto pela luta permanente, gerando esperança, sem a qual a luta fenece; a oposição ao neoliberalismo e a busca da superação da sociedade capitalista (FREIRE, 1992; FREIRE, 2006a).

Em Pedagogia do Oprimido (FREIRE, 1987), o autor analisa as relações entre opressores-oprimidos e o processo de introjeção do dominador pelos dominados; a educação "bancária" e seu autoritarismo; a educação problematizadora, fundada no diálogo; a necessidade, numa prática educativa progressista, de serem os educandos desafiados em sua curiosidade; a presença crítica de educadores e educandos no processo de ensino-aprendizagem em que há uma troca de saberes e experiências, sem que isso signifique a negação da diferença existente entre educadores e educandos (FREIRE, 2006a; PLACIDO; SOUZA, 2017).

Paulo Freire afirma que a prática educativa implica em processos, técnicas, expectativas, desejos, frustrações, na tensão permanente entre prática e teoria, entre liberdade e autoridade, cuja exacerbação não pode ser aceita numa perspectiva democrática, contrária tanto ao autoritarismo como à licenciosidade. A questão fundamental tocada aqui pelo autor, de natureza política e ideológica, é saber quem escolhe os conteúdos do que vai ser ensinado, a favor de quem e de que estará o ensino, contra quem e contra quê; qual é o papel desempenhado pelos alunos na organização programática dos conteúdos, e também, qual o papel dos outros segmentos envolvidos no cotidiano da escola, dentre eles, cozinheiras, zeladores, vigias etc., além desses, qual o papel das famílias, das organizações sociais e da comunidade local. Segundo o autor, "não é possível democratizar a escolha dos conteúdos sem democratizar o seu ensino" (FREIRE, 1992, p. 109-111; FREIRE, 2006a; FREIRE; MENDONÇA, 2019; CASALI, 1998).

Deve-se reiterar que não existe prática educativa neutra, portanto, o educador progressista deve estar atento à coerência entre a sua fala e a sua prática para não impor ao aluno sua "leitura do mundo". No entanto, isso não significa que o educador deva omitir sua posição, mas sim, salientar que existem outras "leituras de mundo", diferentes da sua e talvez até antagônicas a ela (FREIRE, 1992, p. 112-113; FREIRE, 2006a).

Paulo Freire destaca que a tarefa política para o educador progressista consiste em empenhar-se na luta incessante pela democratização da sociedade, que implica na democratização da escola, da programação dos seus conteúdos e de seu ensino. $O$ autor assevera que "uma das tarefas da educação popular progressista, ontem como hoje, é procurar, por meio da compreensão crítica de como se dão os conflitos sociais, ajudar o processo no qual a fraqueza dos oprimidos se vai tornando força capaz de transformar a força dos opressores em fraqueza" (FREIRE, 1992, p. 126).

Diante de argumentos que defendem uma educação supostamente neutra e direcionada somente ao treinamento técnico da força-de-trabalho, o autor pondera que 
MEDEIROS, F. C. N. DE

[...] não é possível formar engenheiros ou pedreiros, físicos ou enfermeiras, dentistas ou torneiros, educadores ou mecânicos, agricultores ou filósofos, pecuaristas ou biólogos sem uma compreensão de nós mesmos enquanto seres históricos, políticos, sociais e culturais; sem uma compreensão de como a sociedade funciona. $E$ isto o treinamento supostamente apenas técnico não dá (FREIRE, 1992, p. 134).

De acordo com Freire (1992), nos dias de hoje, a luta pela unidade na diversidade constitui uma necessidade premente para os diversos segmentos sociais com problemas e lutas específicos (trabalhadores urbanos e rurais, mulheres, negros e indígenas), implicando na decisão, vontade política, mobilização e organização visando a objetivos comuns. Esta demanda remete a uma certa prática educativa coerente com esses objetivos e a uma nova ética fundada no respeito às diferenças. $O$ autor sustenta ainda que as transformações sociais se concretizam quando coincidem a vontade popular, a presença de uma liderança lúcida e o momento histórico propício (FREIRE, 1992, p. 167).

Após apresentar de modo sucinto a trajetória e a obra de Paulo Freire, com destaque para o conteúdo de Pedagogia do Oprimido (FREIRE, 1987), na sequência serão abordadas algumas críticas direcionadas ao autor por parte de forças sociais da direita e também de segmentos da esquerda, visando à problematização e reflexão sobre as propostas pedagógicas de Freire, assim como o posicionamento do autor nesse debate.

\section{PRINCIPAIS CRÍTICAS A PAULO FREIRE}

A obra Pedagogia do Oprimido (FREIRE, 1987) tem sofrido críticas diversas tanto à sua linguagem quanto às suas propostas, consideradas por alguns como ininteligíveis e mesmo irrealizáveis no campo da Educação. A linguagem de Freire seria de tal modo rebuscada e elitista que demonstraria cabalmente sua "falta de respeito pelo povo". $\mathrm{Na}$ verdade, o autor seria "arrogante, elitista e invasor cultural", isto é, um pensador que desrespeita a identidade cultural, de classe, das classes populares - os trabalhadores rurais e urbanos (FREIRE, 2006a).

Nesse aspecto, Paulo Freire contesta seus críticos dizendo que "o momento estético da linguagem deve ser sempre perseguido por todos nós não importa se cientistas rigorosos ou não" (FREIRE, 1992, p. 72). Quanto às suas propostas, o autor assevera que "ensinar não é a pura transferência mecânica do perfil do conteúdo que o professor faz ao aluno, passivo e dócil". Também reitera que "partir do saber que os educandos tenham não significa ficar girando em torno deste saber (...) como a mariposa em volta da luz". Isso porque partir do "saber de experiência feito para superá-lo não é ficar nele" (FREIRE, 1992, p. 70-71). A compreensão de sua proposta político-pedagógica, segundo suas próprias palavras, implica numa"postura aberta e crítica, radical e não sectária, sem a qual se fecha ao texto e se proíbe de com ele aprender algo porque o texto talvez defenda posições antagônicas às do(a) leitor(a). Às vezes, o que é irônico, as posições são apenas diferentes" (FREIRE,1992, p. 76). 
O autor argumenta que as críticas direcionadas às suas propostas se fundam em uma compreensão distorcida da conscientização e em uma visão profundamente ingênua da prática educativa, vista como prática neutra, a serviço do bem-estar da humanidade. Por outro lado, a defesa da suposta neutralidade na prática educativa se configura em "uma prática política indiscutível com que se pretende amaciar a possível rebeldia dos injustiçados" (FREIRE, 1992, p. 77-78).

Freire considera, ainda, que assumir a politicidade e a diretividade da educação implica em vivenciar plenamente a coerência entre a opção democrática e a prática educativa democrática que a acompanha. "Meu dever ético, enquanto um dos sujeitos de uma prática impossivelmente neutra - a educativa - é exprimir o meu respeito às diferenças de ideias e de posições. Meu respeito até mesmo às posições antagônicas às minhas que combato com seriedade e paixão" (FREIRE, 1992, p. 79).

Segundo o autor, como a educação, por sua própria natureza, é diretiva e política, a defesa de sua postura não implica em desrespeito aos(as) educandos(as), ao contrário. "Respeitá-los significa, de um lado, testemunhar a eles minha escolha, defendendo-a; de outro, mostrar-lhes outras possibilidades de opção, enquanto ensino, não importa o quê [...]" (FREIRE, 1992, p. 78).

Ao longo do texto, o autor dá prosseguimento à explicitação de suas ideias, situando as críticas que tem feito ao autoritarismo de intelectuais de esquerda ou de direita que se julgam, respectivamente, "donos" do saber revolucionário ou do saber conservador. Do mesmo modo, o comportamento de universitários que pretendem "conscientizar" trabalhadores rurais ou urbanos sem com eles se conscientizar. Além disso, o messianismo, no fundo ingênuo, de intelectuais que, em nome da libertação das classes trabalhadoras, impõem ou buscam impor a "superioridade" de seu saber acadêmico às "incultas massas" (FREIRE, 1992, p. 80).

Paulo Freire afirma que uma das diferenças fundamentais entre ele e seus críticos reside na sua concepção de que a superação daquelas práticas equivocadas está na superação da ideologia autoritária elitista, "no exercício difícil da virtude da humildade, da coerência, da tolerância, por parte do ou da intelectual progressista. Da coerência que vá diminuindo a distância entre o que dizemos e o que fazemos". Nessa perspectiva, o autor assevera que ensinar consiste num ato criador, um ato crítico e não mecânico. "A curiosidade do(a) professor(a) e dos(as) alunos(as), em ação, se encontra na base do ensinar-aprender" (FREIRE, 1992, p. 80-81).

Portanto, os educadores progressistas jamais devem subestimar ou negar "os saberes de experiência feitos" com os quais os educandos chegam à escola ou aos centros de educação informal, pois não é possível superar o senso comum sem partir dele, por outro lado, não se deve superestimar o saber popular. Isso significa dizer que tanto a negação do saber popular (postura elitista) é contestável, quanto sua mitificação, sua exaltação (postura basista). As duas posições, basista ou elitista, são de tal forma sectárias e presas à sua "verdade" que se tornam incapazes de ir além de si mesmas (Ibidem, 1992, p. 85).

Paulo Freire (1992, p. 85) reitera sua posição de que não propõe "a exaltação ingênua do saber popular pelo educador que ficaria como uma mariposa em torno da luz", conduzindo a prática educativa a um inevitável fracasso. O que ele propõe como 
tarefa política é partir do senso comum, das experiências vividas, dos anseios, dos sonhos, das dificuldades, para buscar sua problematização e sua superação através de um processo individual e coletivo de conscientização, visando à transformação da sociedade. Assim, o educador progressista poderia contribuir nesse processo para a intervenção crítica dos(as) educandos(as) no seu cotidiano como sujeitos históricos e políticos.

É importante frisar que, na visão do autor, o(a) educador(a) também se modifica nesse cenário, trocando seus saberes e suas experiências com os educandos, ensinandoaprendendo e, da mesma forma, se conscientizando. Isso não implica na negação de que o(a) educador(a) possua um conhecimento específico e relevante, mas sim, que o(a) educador(a) assuma uma postura democrática comprometida com um projeto de sociedade que leve em conta o saber popular nas transformações sociopolíticas, culturais e econômicas almejadas.

Contudo, o respeito ao "saber popular", defendido por Paulo Freire, tem sido entendido por alguns como o aprisionamento na localidade, ou seja, na negação da universalidade. Na verdade, o autor defende o contexto local dos alunos como ponto de partida para ampliar sua compreensão do mundo. Se não fosse assim, ele estaria abdicando da "inteligência dialética da realidade", desconsiderando as relações contraditórias entre as parcialidades e a totalidade. $O$ autor nega enfaticamente que seu respeito pelo local possa significar a desqualificação do universal - o regional emerge do local do mesmo modo como o nacional surge do regional, e o continental do nacional como o mundial emerge do continental (FREIRE, 1992, p. 86-87; FREIRE, 2006a).

Muitas das críticas direcionadas ao autor são advindas de pessoas que não leram toda a sua obra e/ou que centraram suas críticas a uma ou outra obra, por exemplo, a Educação como Prática da Liberdade (FREIRE, 2006b) ou Pedagogia do Oprimido (FREIRE, 1987). Dentre essas críticas, é recorrente a menção ao "idealismo" e/ou "democratismo" presentes em suas teses, isto é, a defesa veemente do humanismo, a ausência da categoria classes sociais e da conhecida assertiva de que "a luta de classes é o motor da história" (MARX, 1975), ambas substituídas pelos conceitos de oprimido e de povo (FREIRE, 2006a).

Os pontos centrais levantados por essas críticas, em geral, são: os conceitos de oprimido e de povo, considerados vagos; a afirmação de que o oprimido libertando-se liberta também o opressor; a não declaração de que "a luta de classes é o motor da história"; o tratamento dado à consciência e à subjetividade, sem reduzi-las a mero reflexo das estruturas socioeconômicas; o papel da conscientização que, em Pedagogia do Oprimido, supera, em termos de criticidade, o papel a ela atribuído no livro Educação como prática da liberdade (FREIRE, 2006b); a afirmação de que "a aderência" à realidade das grandes massas camponesas na América Latina exigia que a consciência de classe oprimida passasse, senão antes, pelo menos de forma concomitante pela consciência de homem oprimido (FREIRE, 1992, p. 90; FREIRE, 2006b).

$\mathrm{O}$ autor se defende de seus críticos dizendo que utiliza a referência às classes sociais "não como quem usava um clichê ou como quem se punha temeroso de um possível inspetor ou censor ideológico" (FREIRE, 1992). Dessa forma, ele assume uma postura independente ao elaborar suas teses e considera que suas posições são acertadas e atuais. E diz que não se espantaria se esses mesmos críticos que lhe cobraram, nos anos 1970, a menção constante do conceito de classes, na atualidade lhe 
cobrem justamente o contrário, a retirada do conceito de classes, pois, "já não há classes sociais, cujos conflitos com elas sumiram também", bem ao gosto do discurso neoliberal (FREIRE, 1992; FREIRE, 2006a; FREIRE, 2006b).

Para Paulo Freire, a luta de classes não seria "o" motor da história (MARX, 1975), mas, certamente seria um deles, dentre os quais o sonho, a utopia, a esperança. Por isso, ele vem insistindo, desde Pedagogia do Oprimido (FREIRE, 1987), que não existe utopia verdadeira fora da tensão entre a denúncia de um presente cada vez mais intolerável e o anúncio de um futuro a ser criado, construído, política, estética e eticamente por nós, homens e mulheres (FREIRE, 2006a). "A compreensão da história como possibilidade e não determinismo (...) seria ininteligível sem o sonho, assim como a concepção determinista se sente incompatível com ele e, por isso, o nega" (FREIRE, 1992, p. 92).

$\mathrm{Na}$ atualidade, o legado de Paulo Freire tem sido fundamental para desmontar tentativas de retrocesso no modelo de ensino, com destaque para projetos ultraconservadores, presentes no atual governo brasileiro, que buscam implementar a "Escola sem Partido", uma antítese da tomada de consciência de liberdade e reconhecimento das tendências de autoritarismo, na contramão da pedagogia crítica e humanista do autor.

O projeto de Lei 867/2015 "Escola sem Partido" (RIO DE JANEIRO, 2016) questiona as diretrizes curriculares e o debate político no interior das instituições de ensino que são acusadas de "ideologizar" os alunos. Estas tentativas buscam doutrinar leitores que não conhecem Paulo Freire e sua obra, assim como demonstram resistência a mudanças de caráter progressista na Educação.

Deve-se salientar que tais propostas afrontam a Constituição Federal de 1988, que garante a liberdade de expressão/pensamento e a laicidade na Educação (já que o Estado também é laico), e também a Lei de Diretrizes e Bases da Educação Nacional (LDB, Lei n. 9394/96; BRASIL, 1996), que explicita os principais objetivos educacionais: Art. $2^{\circ}$ "a educação, dever da família e do Estado, é inspirada nos princípios de liberdade e nos ideais de solidariedade humana, tendo por finalidade o pleno desenvolvimento do educando, seu preparo para o exercício da cidadania e a qualificação para o trabalho" (BRASIL, 1996). A LDB também determina que a educação deve ser ministrada com respeito à igualdade de condições de acesso e permanência, com liberdade de práticas e pensamentos, com pluralismo de concepções pedagógicas, dentre outras, visando a garantia da autonomia do professor e a participação ativa do aluno (ALEIXO; ALMEIDA, 2017; DUTRA; MORENO, 2016; BRASIL, 2018; BRASIL, 1996).

Portanto, conforme a Constituição de 1988, a Escola não deve se posicionar a favor ou contra uma única orientação religiosa, reconhecendo a diversidade religiosa existente em nosso país e o respeito a todas as crenças. Na direção contrária desse processo, o referido projeto "Escola sem Partido" visa claramente a determinação de valores (conservadores, moralizantes e religiosos fundamentalistas) a serem defendidos no âmbito da Escola, a negação do debate político nesse espaço (ancorado numa pseudoneutralidade) e a interferência na prática pedagógica do professor e na sua autonomia em sala de aula (ALEIXO; ALMEIDA, 2017; DUTRA; MORENO, 2016; BRASIL, 2018; FRIGOTTO, 2017).

Deve-se salientar ainda a tentativa desses segmentos ultraconservadores de retirar de Paulo Freire o Patronato da Educação Brasileira, como já referido. Para esvaziar 
MEDEIROS, F. C. N. DE

essa iniciativa, foi criado o Coletivo Paulo Freire por uma Educação Democrática, organizado por Luiza Erundina, Ana Maria Araújo Freire (viúva do autor) e Daniel Cara. Assim sendo, diante de um quadro de intolerância e ataques à Democracia e aos Direitos Humanos, o legado de Paulo Freire é cada vez mais imprescindível (GUIMARÃES, 2018; FREIRE; MENDONÇA, 2017).

\section{CONCLUSÃO}

No Brasil, após as eleições de 2018, com a ascensão da extrema-direita à presidência da República, configura-se um quadro complexo e desafiador caracterizado pelo autoritarismo, vinculado a um fundamentalismo religioso, voltado a uma ofensiva brutal às conquistas democráticas após a promulgação da Constituição Federal de 1988. Tal ofensiva tem se pautado no negacionismo, na desqualificação da Ciência, da Educação, da Cultura e no desmonte das Políticas Públicas.

No que concerne às críticas dirigidas a Paulo Freire, destacam-se aquelas de pessoas que não leram toda sua obra, restringindo-se a uma ou outra obra, bem como o seu desconhecimento, ou ainda aquelas que possuem discordâncias políticoideológicas, muitas vezes, fora de contexto e equivocadas.

Portanto, as contribuições do autor no campo da educação são inegáveis, a despeito de críticas e discordâncias, que são bem-vindas ao debate democrático, caracterizado pelo pluralismo de ideias e propostas pedagógicas, pela laicidade e respeito ao(a) educando(a) como um sujeito de direitos em formação, e à diversidade humana, como preconizam a Constituição Federal de 1988 e a Lei de Diretrizes e Bases da Educação Nacional (BRASIL, 1988; BRASIL, 1996; BRASIL, 2018).

Na direção contrária à perspectiva libertadora de Paulo Freire encontra-se a tentativa de segmentos ultraconservadores, ancorados em discursos e ações de cunho moralista, religioso fundamentalista e pseudocientífico, de desqualificar o legado desse grande educador, assim como na negação do debate no interior das instituições de ensino e no papel político desempenhado pela educação e pelo professor na sociedade. Tais medidas são defendidas pelo projeto de Lei 867/2015, "Escola sem Partido" (RIO DE JANEIRO, 2016), que traz o risco do retrocesso das conquistas democráticas advindas da Constituição Federal de 1988. Particularmente, os artigos 205 e 206 que preconizam "a liberdade de aprender, ensinar, pesquisar e divulgar o pensamento, a arte e o saber, o pluralismo de ideias e de concepções pedagógicas" (BRASIL, 1988; BRASIL, 1996; BRASIL, 2018; ALEIXO; ALMEIDA, 2017; DUTRA; MORENO, 2016; FRIGOTTO, 2017).

Deve-se ressaltar ainda que, nesse contexto adverso, várias organizações, instituições e movimentos da sociedade civil vêm construindo uma rede de resistência democrática para se contrapor à essa guinada ultraconservadora de ataques à Democracia, aos Direitos Humanos, às Universidades Públicas, aos segmentos progressistas e de esquerda em nosso país.

Dentre essas ações e debates concretos destaca-se, na área da educação, o Manual de Defesa contra a Censura nas Escolas (BRASIL, 2018), lançado em novembro de 2018, com o apoio do Ministério Público Federal (MPF), da Procuradoria Federal dos Direitos do Cidadão (PFDC) e da Fundação Malala, criada para defender os direitos das meninas e mulheres à educação em várias partes do mundo (BRASIL, 2018). Desse modo, na direção oposta desses segmentos ultraconservadores 
mencionados, destaca-se, no debate sobre a educação, a perspectiva libertadora de Paulo Freire, na qual é possível vislumbrar o papel da escola e do professor, em conjunto com outras instituições democráticas e segmentos progressistas. Destacando-se ainda a construção coletiva de uma nova sociabilidade, onde todos(as) tenham acesso aos direitos, bens e serviços que caracterizam a vida moderna, superando a luta diária pela sobrevivência e tornando-se seres humanos integrais, capazes de desenvolver e realizar todo o seu potencial antes negado.

Essa árdua e gigantesca tarefa política coletiva implica na tomada de consciência pelos sujeitos sociais dessa necessidade e possibilidade, no seu engajamento e compromisso com um projeto de sociedade radicalmente democrática que vise a superação do individualismo, pautado na lógica da propriedade privada e do mercado, que respalda o conservadorismo e o autoritarismo na contemporaneidade. Tal quadro adverso demonstra o risco de retrocesso no padrão civilizatório que caracteriza as sociedades democráticas modernas e nos desafia à uma crítica reflexiva e ações concretas na defesa vigorosa e aguerrida desse relevante legado, visando a preservar o futuro das próximas gerações.

Artigo recebido em: 07/08/2020 Aprovado para publicação em: 13/10/2020

THE LIBERATING PERSPECTIVE OF EDUCATION: AN ANALYSIS OF FREIRE'S THOUGHT AND HIS CONTRIBUTIONS IN CONTEMPORANEITY

ABSTRACT: The purpose of this article is to introduce a debate about Paulo Freire and his contributions to the Brazilian education. In this sense, the fundamental elements of his thinking, his works and pedagogical proposals are addressed, as well as the main criticisms of this perspective, including the School without Party project. In addition, it is presented Paulo Freire's positions in relation to some of these criticisms and the author's view on the role of the education in society. In order to reach the scope of this article, the methodological resource used is based on a bibliographic and documentary research associated with a critical analysis of the Brazilian reality in contemporary times. It is concluded that Paulo Freire's proposals remain current and is essential to tackle the great and complex challenges of education in Brazil.

KEYWORDS: Paulo Freire. Liberating education. Pedagogical proposals. Conservatism.

LA PERSPECTIVA LIBERADORA DE LA EDUCACIÓN: UN ANÁLISIS DEL PENSAMIENTO DE FREIRE Y SUS CONTRIBUCIONES EN LA CONTEMPORANEIDAD

RESUMEN: El propósito de este artículo es presentar un debate sobre Paulo Freire y sus contribuciones a la educación brasileña. En este sentido, se abordan los elementos fundamentales de su pensamiento, de sus obras y propuestas pedagógicas, así como las principales críticas de esta perspectiva, incluido el proyecto Escuela sin Partido. A continuación, se presentan las posiciones de Paulo Freire con respecto a algunas de estas críticas y la opinión del autor sobre el 
MEDEIROS, F. C. N. DE

papel de la educación en la sociedad. Para lograr el alcance de este artículo, el recurso metodológico utilizado se basa en una investigación bibliográfica y documental asociada con un análisis crítico de la realidad brasileña en los tempos contemporáneos. Se concluye que las propuestas de Paulo Freire siguen siendo actuales y esenciales para enfrentar los grandes y complejos desafíos de la educación en Brasil.

PALABRAS-CLAVE: Paulo Freire. Educación liberadora. Propuestas pedagógicas. Conservatismo.

\section{REFERÊNCIAS}

ALEIXO, K. M.S.; ALMEIDA, C.B. Escola sem Partido: há interferência na autonomia do professor? Fundação CECIERJ. $2017 . \quad$ Disponível em: http://educacaopublica.cecierj.edu.br/revista/?p=41412. Acesso em: 07 ago. 2020.

BRASIL. Lei n. 12.612 de 13 de abril de 2012 - Declara o Educador Paulo Freire Patrono da Educação Brasileira. Brasília, DF: Presidência da República, 2012.

BRASIL. Constituição da República Federativa do Brasil. Brasília/DF: Senado Federal, 1988.

BRASIL. Lei de Diretrizes e Bases da Educação Nacional. Lei n. 9.394/96 de 20 de dezembro de 1996. Brasília/DF: Senado Federal, 1996.

BRASIL. Manual de Defesa contra a Censura nas Escolas. Ministério Público Federal (MPF); Procuradoria Federal dos Direitos do Cidadão (PFDC); Fundação Malala. Brasília, novembro de 2018. Disponível em: www.manualdedefesadasescolas.org.br. Acesso em: 07 ago. 2020.

CASALI, A. Paulo Freire: o educador na história. Revista Educação, Sociedade e Culturas, n. 10, 1998, p. 95-109. São Paulo: Pontifícia Universidade Católica de São Paulo, 1998.

CHAUÍ, M. Cultura e Democracia. 11ª ed. São Paulo: Cortez, 2006.

DUTRA, C.; MORENO, C. Escola sem Partido. Estratégia golpista para calar a educação: o projeto da direita para a educação dissemina concepções e práticas preconceituosas, discriminatórias e excludentes (2016). Revista Carta Capital online. Disponível em: http://www.apeoesp.org.br/noticias/noticias-2016/escola-sem-partido-estrategiagolpista-para-calar-a-educacao/. Acesso em: 07 ago. 2020.

FLACH, S.F.; DARCOLETO, C. A.S. O Direito à Educação em Risco: a influência dos "sem partido" e dos "sem escola" na legislação educacional brasileira. Revista de Políticas Públicas. Universidade Federal do Maranhão. Programa de Pós Graduação em Políticas Públicas. 2019. Disponível em: http://dx.doi.org/10.18764/2178-2865.v23n2p605-620. Acesso em: 07 ago. 2020. 
FREIRE, A.M.A.; MENDONÇA, E.F. Direitos Humanos e Educação Libertadora: gestão democrática da educação pública na cidade de São Paulo. $1^{\text {a }}$ ed. Rio de Janeiro/ São Paulo: Paz e Terra, 2019.

FREIRE, A.M.A. Paulo Freire: Uma História de Vida. Indaiatuba, São Paulo: Villa das Letras, 2006 a.

FREIRE, P.; SHOR, I. Medo e Ousadia: O Cotidiano do Professor. Rio de Janeiro: Paz e Terra, 2013.

FREIRE, P. Educação Como Prática da Liberdade. 29a ed. Rio de Janeiro: Paz e Terra, $2006 b$.

FREIRE, P. Pedagogia da Tolerância. Organização, apresentação e notas de Ana Maria Araújo Freire. São Paulo: Editora Unesp, 2005. (Série Paulo Freire).

FREIRE, P. Pedagogia dos Sonhos Possíveis. Organização, apresentação e notas de Ana Maria Araújo Freire. São Paulo: Editora Unesp, 2001. (Série Paulo Freire).

FREIRE, P. Pedagogia da Indignação: cartas pedagógicas e outros escritos. Apresentação e organização de Ana Maria Araújo Freire. São Paulo: Editora Unesp, 2000.

FREIRE, P. Pedagogia da Autonomia: saberes necessários à prática educativa. $6^{a}$ ed. São Paulo: Paz e Terra, 1996. (Coleção Leitura).

FREIRE, P. À Sombra desta Mangueira. São Paulo: Olho D'Água, 1995.

FREIRE, P. Cartas a Cristina: reflexões sobre minha vida e minha práxis. Notas de Ana Maria Araújo Freire. São Paulo: Paz e Terra, 1994.

FREIRE, Paulo. Professora sim, tia não. cartas a quem ousa ensinar. São Paulo: Olho D’Água, 1993.

FREIRE, P. Política e Educação. São Paulo: Cortez, 1993.

FREIRE, P. Pedagogia da Esperança: um reencontro com a Pedagogia do Oprimido. Notas de Ana Maria Araújo Freire. 13ª ed. Rio de Janeiro: Paz e Terra, 1992.

FREIRE, P. A Educação na Cidade. São Paulo: Cortez, 1991.

FREIRE, P. Pedagogia do Oprimido. 17a ed. Rio de Janeiro: Paz e Terra, 1987. (Coleção O Mundo Hoje, vol. 21).

FREIRE, P. A Importância do Ato de Ler em Três Artigos que se Completam. Cortez: Autores Associados, 1982.

Inter-Ação, Goiânia, v.45, n.3, p. 874-889, set./dez. 2020. Disponível em: <http://dx.doi.org/10.5216/ia.v45i3.64860>. 
MEDEIROS, F. C. N. DE

FRIGOTTO, G. (Org.). Escola 'sem' partido. esfinge que ameaça a educação e a sociedade brasileira. Rio de Janeiro: LPP/UERJ, 2017.

GADOTTI, M. Convite à leitura de Paulo Freire. 2a ed. São Paulo: Scipione, 2001.

GIL, A.C. Métodos e Técnicas de Pesquisa Social. 6a ed. São Paulo: Atlas, 2012.

GUIMARÃES, J. Paulo Freire, 97 anos: o legado do brasileiro que ensinou o mundo a ler a si mesmo. Revista Brasil de Fato. São Paulo, 19 de agosto de 2018. Disponível em: https://www.brasildefato.com.br/2018/09/19/paulo-freire-97-anos-o-legado-dobrasileiro-que-ensinou-o-mundo-a-ler-a-si-mesmo/. Acesso em: 07 ago. 2020.

LOPES, C. R. et al. Educação e Cultura em Saúde à Luz de Paulo Freire. Revista de Enfermagem UFPE On Line, Recife, 11 (12): 5122-8, dez. 2017.

LÖWY, M. A extrema-direita: um fenômeno global. Revista Esquerda on line. 2019. Disponível em: https://esquerdaonline.com.br/2019/01/15/a-extrema-direita-umfenomeno-global/. Acesso em: 07 ago. 2020.

MARX, K. Manifesto do Partido Comunista. Lisboa: Avante, 1975.

MENDES, G.L. Sete Pontos para entender o porquê Paulo Freire é o maior intelectual brasileiro. Revista Forum. São Paulo, 02 de agosto de 2019. Disponível em: https://revistaforum.com.br/brasil/sete-pontos-para-entender-o-porque-paulo-freire-eo-maior-intelectual-brasileiro-no-mundo/. Acesso em: 07 ago. 2020.

MIRANDA, M.G. O Neoliberalismo como Ofensiva Conservadora à Educação Brasileira. Revista Inter-Ação, Goiânia, v. 45, n. 1-15, jan./abr. 2020. Disponível em: http://dx.doi.org/10.5216/ia.v45i1.62691. Acesso em: 07 ago. 2020.

PLÁCIDO, L.R.; SOUZA, T. B. O Método Paulo Freire: primeiras aproximações. Revista Científica Eletrônica da Pedagogia. Ano XVI, n. 28, jan. 2017, periódico semestral. Faculdade de Ensino superior e Formação Integral de Garça, São Paulo. Disponível em: http://faef.revista.inf.br/imagens_arquivos/arquivos_destaque/psR18Fk8vYsjPac_20183-17-11-34-46.pdf. Acesso em: 07 ago. 2020.

RIO DE JANEIRO. Projeto de Lei n. 867 de 2015. Rio de Janeiro: Assembleia Legislativa do Rio de Janeiro/Alerj, 2016.

VAZQUEZ, A. S. Filosofia da Práxis. Rio de Janeiro: Paz e Terra, 1977.

VEIGA, E. Paulo Freire: como o legado do educador brasileiro é visto no exterior. $B B C$ News Brasil. Disponível em: https://www.bbc.com/portuguese/brasil-46830942. Acesso em: 07 ago. 2020.

Inter-Ação, Goiânia, v.45, n.3, p. 874-889, set./dez. 2020. Disponível em: <http://dx.doi.org/10.5216/ia.v45i3.64860>. 
ZAIUTH, G.; HAYASHI, M.C.P.I. A Apropriação do Referencial Teórico de Paulo Freire nos Estudos sobre Educação CTS. Revista Brasileira de Ciência, Tecnologia e Sociedade, v. 2, n. 1, p. 278-292, jan./jun. 2011.

Flávia Cavalcante Nicolis de mederRos: Possui Doutorado em Serviço Social pela Universidade Federal do Rio de Janeiro (UFRJ/2006); Mestrado em Serviço Social pela Universidade Federal do Rio de Janeiro (UFRJ/1996); Especialização em Docência do Ensino Superior pelas Faculdades Integradas de Jacarepaguá (FIJ/ RJ/ 2007); Graduação em Serviço Social pela Universidade Federal de Juiz de Fora (UFJF/1992). Orcid: https://orcid.org/0000-0003-0044-6574

E-mail: fnicolis@hotmail.com

Este periódico utiliza a licença Creative Commons Attribution 3.0, para periódicos de acesso aberto (Open Archives Iniciative - OAI). 